\title{
De repositorios académicos, redes sociales académicas y demás ecosistema: elementos de fidelización con el usuario
}

José Carlos Morillo Moreno | Área de Producción Científica, Proceso Técnico y Automatización, Biblioteca Universitaria de Huelva

URL de la contribución <www.iaph.es/revistaph/index.php/revistaph/article/view/4638>

La Universidad de Huelva (UHU) creó en 2008 el repositorio institucional Arias Montano (AM), que nace con la finalidad y el objetivo de archivar, preservar y difundir los documentos generados en el transcurso de la actividad investigadora e institucional. En 2010 se adhidirió institucionalmente a la Declaración de Berlín y, en 2015, la UHU aprobó su Política Institucional de Acceso Abierto a la Producción Científica y Académica.

Pasados doce años desde la creación de nuestro repositorio, podemos valorar qué elementos fidelizan más a nuestros usuarios y usuarias y qué otros son mejorables. Antes, y en relación con el tema de las redes sociales académicas, apuntamos brevemente que la Biblioteca Universitaria de Huelva ha establecido cierta estrategia de apoyo a estas redes basada en:

> Considerarlas elemento vinculado a la estrategia de identidad digital del investigador y no vinculadas específicamente al repositorio, auque las hemos usado, en ocasiones, como alerta para la producción científica.

$>$ Ofrecemos asesoramiento a consultas de nuestros investigadores y elaboramos contenidos de ayuda, pero asignando inferior relevancia que a ORCID, Google Citations, etc.

Aún conscientes de las dificultades y altibajos propios del devenir de cualquier repositorio, consideramos puntos fuertes en la fidelización de las personas que se dedican a la investigación:

1. Marca Biblioteca: repositorio académico como servicio de apoyo a la investigación. Primero fue el servicio y luego la ley (2011). Nuestra comunidad parece haber

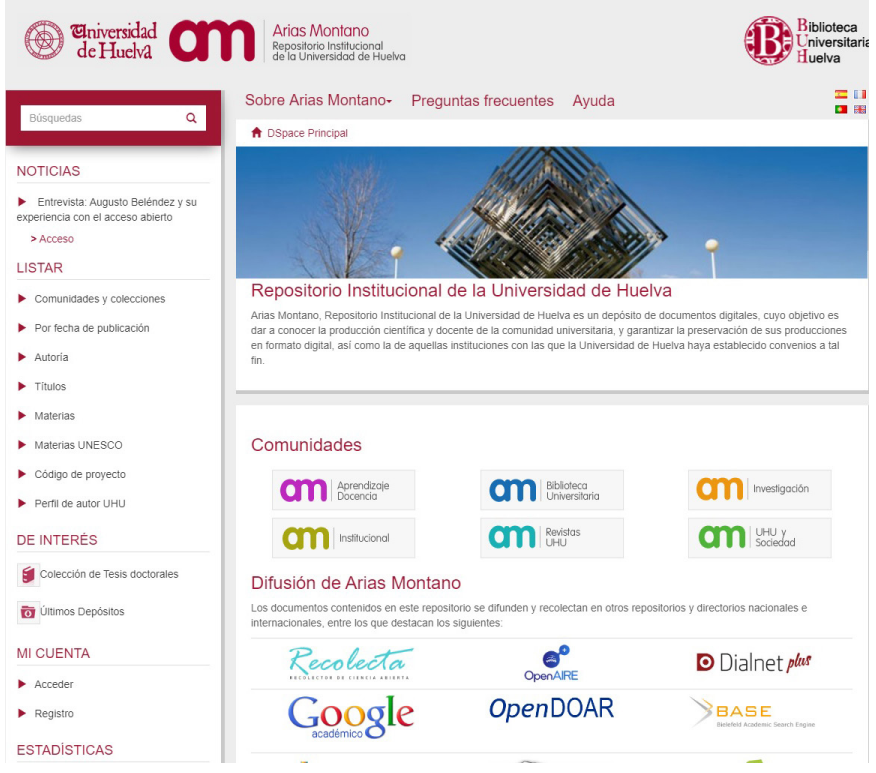

Repositorio institucional Arias Montano

interiorizado que el repositorio forma parte del conjunto de recursos y servicios estratégicos bibliotecarios: catálogo, discovery, recursos electrónicos, etc.

2. La norma/la ley: muchos de nuestros investigadores e investigadoras han entendido que AM da soporte al cumplimiento de la Ley de la Ciencia, el Real Decreto 99/2011 que regula las enseñanzas de doctorado y otras normas nacionales y supranacionales.

3. La política institucional, en la misma línea que el punto anterior y en forma de mandatos y recomendaciones. En la UHU hemos alcanzado cierta madurez que se evidencia en su Política de Acceso Abierto a la Producción Científica y Académica de la UHU (2015) y también en las EPIT (Estrategias de Política de Investigación 
a debate Repositorios y redes sociales académicas para la transferencia del conocimiento abierto

| coordina Remedios Melero Melero

y Transferencia) de los últimos años. En la EPIT UHU 2016-2017 el Repositorio mereció un eje completo. En la EPIT 2020 el acceso a la financiación de proyectos UHU pasa por el alta para auto-archivo en Arias Montano.

4. Formación docente y repositorio UHU. Tras años de talleres diversos, desde el 2019 formamos parte del plan de Formación del Profesorado de la UHU, en su eje 3/ línea 7: formación para la investigación. Participamos con el curso Acceso abierto a la producción científica. Repositorio Científico Arias Montano, que compone un itinerario formativo no oficial junto con: Perfiles del investigador/a y la visibilidad de la actividad investigadora. Dos cursos independientes que constituyen piezas de una estrategia común, lo que deseamos que sea un kit básico formativo del investigador en la Universidad de Huelva.

5. Interoperabilidad, estándares y metadatos: garantizando y aumentando la difusión y visibilidad mediante indexación y recolección sin esfuerzo para los investigadores. La presencia en plataformas como Google Académico, que indexa AM, es esencial. También desplegamos acciones de enriquecimiento de metadatos mediante la colaboración alumnado en prácticas de Filología que enriquecen, con descriptores en inglés, contenidos del repositorio.

6. Marca institucional y sociedad: recogiendo en Arias Montano contenidos institucionales, discursos, informes, videoteca, fonoteca, fototeca, producción cultural, revistas propias y vinculadas, contenidos y proyectos de digitalización resultantes de convenios con otras instituciones del entorno.

Si los anteriores son los que considero pilares de la fidelización, también hay que mencionar puntos débiles. Coinciden, precisamente, con aquellos en los que parecen desenvolverse mejor las redes sociales académicas, destacando dos:

> Servicios al investigador: valor ampliamente aceptado en los repositorios, como evidencia el criterio 8 que

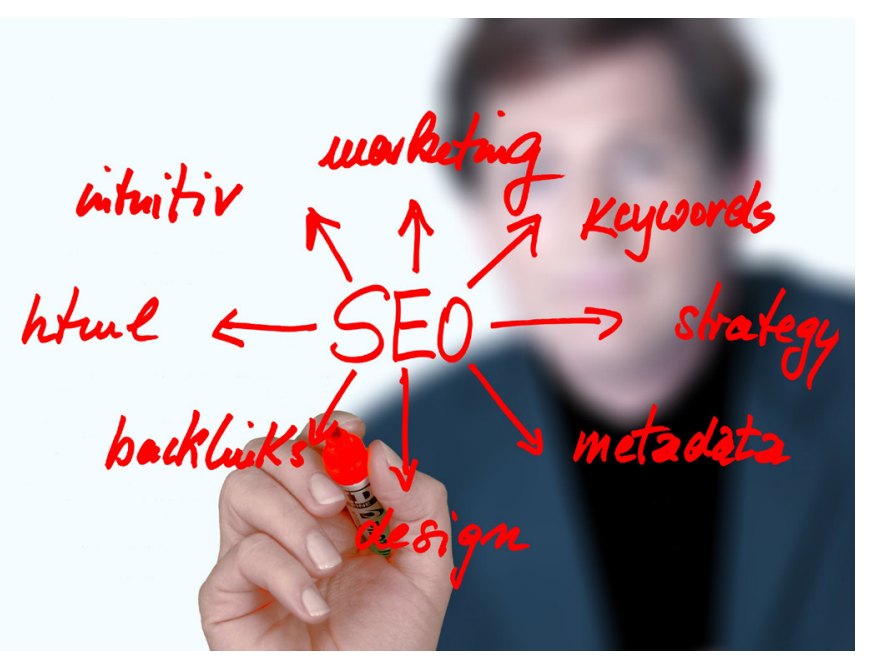

La difusión y visibilidad se incrementan mediante la indexación y enriquecimiento de los metadatos de los trabajos

actualiza la tercera edición de la guía de evaluación de Recolecta FECYT de repositorios titulado "Servicios y funcionalidades de valor añadido". Ya es común en repositorios contar con hipervínculos a identificadores y perfiles, altmétricas, widgets de citación, estadísticas, herramientas de exportación, perfiles y podríamos continuar con la lista. Pero todas estas herramientas quedan lejos de la gran batería de funcionalidades que proporcionan las redes sociales académicas y concretamente la amigabilidad con la cual se presentan sus prestaciones sociales (conversaciones, recomendaciones, etc.).

> Las herramientas de comunicación electrónica con el usuario: alertas y avisos, listas, correos. Los repositorios cuentan con canales algo torpes de comunicación con el investigador, siendo referente las que despliegan redes como ResearchGate.

Como consideraciones finales, diría que:

$>$ Evidentemente la filiación institucional, la norma, las políticas institucionales y la acción formativa al investigador constituye elementos fundamentales de fidelización, generando una relación estable y duradera. Ahora bien, en una esfera diferente a la que proporcionan las redes 
sociales académicas (consultar correo electrónico a la lista INCYT del profesor Emilio Delgado López-Cózar para una clarísima representación del escenario) ${ }^{1}$.

> Desde la Biblioteca Universitaria de Huelva animamos a nuestros investigadores e investigadoras a una estrategia tanto individual como colectiva de difusión y visibilidad de la producción científica y que puedan replicar según disciplinas, grupos y centros de investigación y en la cual incluimos también las redes sociales académicas.

> Sugerimos itinerarios para el depósito de la producción científica y perfiles que permitan el ahorro de esfuerzos. En las redes sociales podrá ser fácil crear y subir contenidos, pero se complejiza cada vez más la limpieza de los mismos. En Arias Montano conviven el auto-archivo y el archivo delegado y pasan por el filtro y mantenimiento de los bibliotecarios. Además, hay elementos en que las redes sociales académicas no tienen fácil encaje. Así, Arias Montano permite la exportación de producción científica con ficheros BibTex que ORCID o Google Citations aceptan, pero no ResearchGate, por poner un ejemplo. Desconozco los datos de inactividad de perfiles en las redes sociales académicas, que sería una información altamente interesante.

$>$ Como responsables del repositorio institucional entendemos que estamos dando respuesta a las Recomendaciones para la implementación del artículo 37 Difusión en Acceso Abierto de la Ley de la Ciencia, la Tecnología y la Innovación elaboradas por la Comisión de Seguimiento de la FECYT donde se dice: "Los investigadores han de recibir la formación y adquirir los hábitos y competencias que faciliten que su producción científica esté en acceso abierto". Consideramos esto como ejemplo de la colaboración entre profesionales de la biblioteconomía e investigadores.

> Nos interesa especialmente el impacto que, a corto plazo, la implicación del investigador con el acceso abierto tendrá en la evaluación docente, contexto en el que previsiblemente los repositorios académicos adqui- rirán un papel relevante. Se hace referencia ya a esta cuestión en distintas normas y planes, pero aún no conocemos cómo se materializará.

\section{NOTA}

1. DELGADO LÓPEZ-CÓZAR, E. La hoja de ruta verde de la comunicación científica ¿Qué podemos hacer para cambiar las cosas? Lista INCYT, 31 de octubre de $2018<$ https://listserv.rediris.es/cgi-bin/wa?A2=ind1810E\&L=INCYT\&P=R2316> [Consulta: 16/04/2020] 